DOI: 10.12731/wsd-2017-2-168-183

УДК 159.9.072.43

\title{
СОВЛАДАНИЕ СО СТРЕССОВЫМИ И ПРОБЛЕМНЫМИ ДЛЯ ЛИЧНОСТИ СИТУАЦИЯМИ И СЛАБОВЫРАЖЕННЫЕ ДЕПРЕССИВНЫЕ РАССТРОЙСТВА У ЛИЦ МОЛОДОГО ВОЗРАСТА В ПЕРИОДЕ АДАПТАЦИИ
}

\author{
Улюкин И.М., Григорьев С.Г.
}

Цель. Изучить взаимосвязь совладания со стрессовыми и проблемными для личности ситуациями и слабовыраженных депрессивных расстройств у лии молодого возраста.

Материалы и методы. Обследовано 100 практически студентов первого курса (группь «М» и «Ж», в соотнотении 1/1) педагогического университета в периоде адаптации к учебному прочессу. Для психологической диагностики совладающего со стрессом поведения использована «Методика для психологической диагностики способов совладания со стрессовыми и проблемными для личности ситуациями» [Вассерман Л.И., и др., 2009]. Исследовались такие копинг-стратегии, как «Конфронтация», "Дистанцирование», "Самоконтроль», "Поиск сочиальной поддержки», «Принятие ответственности», «Бегство-избегание», «Планирование решения проблемы», «Положительная переоценка». Определение депрессивного фона настроения в клинически малой степени выраженности или неопределённости, и оценивание принадлежности синдрома к определённому классу депрессий проведено по «Шкале для экспресс-психологической диагностики слабоструктурированных депрессивных расстройств» [Беспалько И.Г., 2004]. Каждый участник подписывал форму информированного согласия на обследование. Статистическая обработка данных осуществлялась с помощью пакета прикладных программ Statistica 7.0.

Результаты. Выявлены и проанализированы гендерная структура копинг-стратегий и их связь со слабовыраженными депрессивными расстройствами.

Заключение. Показано, что для успешной адаптации студентов к учебному процессу необходимы создание в обучающих группах благо- 
приятного психолого-педагогического микроклимата с целью формирования и индивидуализации умений самоорганизации в соответствии с личностныли особенностями студентов; взаимодействие со студентами для преодоления трудностей в учебе; раннее выявление студентов группь риска и предупреждение у них возможных нарушений адаптации в период социализации посредством (при необходимости) психодиагностики и консультирования; решения личностных проблем в адаптационный период посредством оказания консультативной или иной другой помощчи для предупреждений отклоняющегося поведения.

Ключевые слова: практически здоровые молодые люди; психологическая диагностика; слабовыраженные депрессивные расстройства; стратегии совладающего поведения.

\title{
COPING WITH STRESSFUL AND PROBLEMATIC FOR THE INDIVIDUAL SITUATION AND WEAKY EXPRESSED DEPRESSIVE DISORDERS IN YOUNG PEOPLE IN THE PERIOD OF ADAPTATION
}

\author{
Uliukin I.M., Grigorjev S.G.
}

Background: To investigate the relationship of coping with stressful and problematic for the individual situations and weakly expressed depressive disorders in young people.

Materials and methods: A total of almost 100 first-year students (groups " $M$ " and " $F$ ", in proportion 1/1) of Pedagogical University in the period of adaptation to the educational process were examined. For psychological diagnosis of coping with stress behavior the "Methodology for psychological diagnosis methods of coping with stressful and problematic situations for the individual" [Wasserman L.I., et al., 2009] was used. We investigated the coping strategies such as "Confrontation", "Distancing", " Self-control ", "Search for social support", "Taking responsibility", "Escape-avoidance”, "Planning to solve the problem," "Positive reappraisal". Determination of the background of depressive mood in clinically low severity or uncertainty, and evaluation of a syndrome belonging to a certain class of depression conducted by the "Scale for rapid psychological diagnosis semistructured depressive disorders" [Bespal'ko I.G., 2004]. 
Results: The gender structure of coping strategies and their relationship are revealed and analyzed.

Conclusion: Thus, it's need for successful adaptation of students to the educational process to create in training groups a favorable psycho-pedagogical climate in order to create self-organizing skills and individualization according to the personal characteristics of students; to interact with students to overcome the difficulties in their studies; it's need an early identification of students at risk and preventing their possible disadaptation of violations during the socialization of means (if necessary) a psycho-diagnostics and counseling; to solve personal problems in the adaptation period by providing advice or other assistance for the warning of deviant behavior.

Keywords: Able-bodied young people; psychologic testing; latent depression; coping behaviour.

\section{Введение}

Известно, что высокая распространенность аффективных расстройств и особенно психогенных депрессий связана не только с социально-экономическими преобразованиями в современном обществе, но и с патоморфозом психогений, особенностью которых является непсихотический уровень с преобладанием астенической и сомато-вегетативной симптоматики [15]. Так, распространенность только дистимий (слабо выраженных, хронически протекающих субсиндромальных депрессий) уже к 2000 г. составляла, по разным данных, от 3,1 до 8,6\% [1]. По уточненному прогнозу BO3 (2012), к 2030 г. депрессия будет являться ведущей причиной инвалидизации населения планеты [2], так как полагают, что это обусловлено в том числе и тем, что одним из неблагоприятных факторов является утрата, в связи с научно-техническим прогрессом, физической компоненты труда и увеличение нагрузки на интеллектуальную и эмоциональную сферы.

Считается, что процесс психической адаптации позволяет человеку устанавливать оптимальные соотношения с окружающей средой и вместе с тем удовлетворять собственные актуальные потребности, не нарушая адекватного соответствия между его психическими и физиологическими характеристиками, с одной стороны, и требованиями среды - с другой [3]. Поэтому способ взаимодействия личности с проблемной (стрессовой) или кризисной ситуацией важен как с точки зрения изменения ситуации, так и для регуляции эмоционального состояния, вызванного проблемной ситуацией (точнее, ее оценкой). С другой стороны, трудность интерпретации донозологических исследований связана со значительными вариациями индивидуальных пара- 
метров, характеризующих отдельные системы организма, которые обусловлены возрастом и полом обследуемых, временем суток, сезоном года, когда проводятся исследования, уровнем адаптированности людей к воздействию региональных факторов [6; 8]. Поэтому эти вопросы изучены недостаточно.

Целью исследования явилось изучение совладания со стрессовыми и проблемными для личности ситуациями и слабовыраженные депрессивные расстройства у лиц молодого возраста в периоде адаптации к учебному процессу.

\section{Материалы и методы исследования}

Для достижения поставленной цели обследовано 100 практически здоровых студентов первого курса педагогического университета в периоде их адаптации к учебному процессу (м / ж=1 / 1, средний возраст $18,3 \pm 0,7$ / 17,8 $\pm 0,5$ лет).

Единой классификации копинга или типов копинг-стратегий в настоящее время не существует. Нами для психологической диагностики совладающего со стрессом поведения использована «Методика для психологической диагностики способов совладания со стрессовыми и проблемными для личности ситуациями» [5]. Исследовались такие копинг-стратегии, как «Конфронтация», «Дистанцирование», «Самоконтроль», «Поиск социальной поддержки», «Принятие ответственности», «Бегство-избегание», «Планирование решения проблемы», «Положительная переоценка».

Определение депрессивного фона настроения в клинически малой степени выраженности или неопределённости, и оценивание принадлежности синдрома к определённому классу депрессий проведено по «Шкале для экспресс-психологической диагностики слабоструктурированных депрессивных расстройств» [4]. Для выявления общего депрессивного фона применена шкала 1 «Д-N» (утверждения, составляющие шкалу, отражают основные клинические проявления депрессии), для первичной оценки качества депрессии (то есть, отнесения депрессии, диагностируемой первой шкалой или к уровню «мягких» депрессий, близких к невротическому спектру, или к «большой» депрессии) использована шкала 2 «МДП-Д, неврозы» (эта шкала различается в зависимости от пола; в шкалу для мужчин входит 47 вопросов, для женщин - 43 вопроса).

Дизайн работы осуществлялся в соответствии с принципами доказательной медицины [13]. Исследование было проверяющим гипотезу, рандомизированным, открытым, контролируемым. У всех пациентов было получено добровольное информированное согласие на участие в исследовании. 
Работа выполнена в соответствии с положениями «Конвенции о защите личности в связи с автоматической обработкой персональных данных» [10]. У всех респондентов было получено добровольное информированное согласие на участие в исследовании. Исследование проводилось групповым методом при его длительности 40 мин. Контрольными показателями явились данные, приведенные авторами использованных методик.

Статистическая обработка материалов исследования проведена с использованием пакета прикладных программ «Statistica for Windows» [14]. При математико-статистической обработке полученных результатов применяли методы описательной статистики (процентные показатели, расчет среднего значения и стандартного отклонения). Полученные количественные признаки представили в виде $\mathrm{M} \pm \mathrm{m}$, где $\mathrm{M}-$ среднее значение признака, $\mathrm{m}$ - стандартная ошибка средней величины. После оценки распределения изучаемых нами показателей на соответствие его нормальному или близкому к нему распределению и доказательства этого соответствия для сравнения полученных данных использовался t-критерий Стьюдента. В качестве значимых принимались результаты со степенью достоверности не ниже $95 \%(\mathrm{p}<0,05)$. С помощью коэффициента корреляции Спирмена определяли силу и статистическую значимость связи между ранговыми показателями.

По шкале Чеддока, корреляция (r) при значении от 0 до 0,3 расценивается как очень слабая, от 0,3 до 0,5 как слабая, от 0, 5 до 0,7 как средняя, от 0,7 до 0,9 как высокая, от 0,9 до 1 как очень высокая. Различия качественных показателей определялись по тесту хи-квадрата Пирсона.

Данное исследование для подобного контингента лиц выполнено впервые.

\section{Результаты исследования и их обсуждение}

В результате экспериментально-психологического обследования респондентов установлено, что цифровые показатели выраженности стратегий совладающего поведения как в группе мужчин («М»), так и в группе женщин («Ж»), значимо не отличались от показателей лиц контрольной группы («К»), установленных авторами методики несколькими годами ранее (Таб. 1). Однако значительно меньший, по сравнению с данными группы исследования, показатель среднего отклонения в группе «К», вероятно, свидетельствует об иных подходах к психологическому отбору абитуриентов. 


\begin{tabular}{|c|c|c|c|c|c|c|c|c|c|c|c|}
\hline \multirow{11}{*}{ 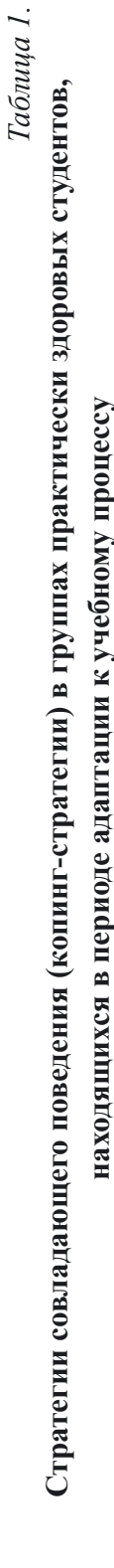 } & \multicolumn{3}{|c|}{ 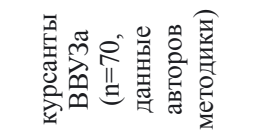 } & 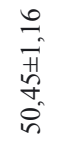 & $\begin{array}{l}0 \\
\text { से } \\
\text { तू } \\
\text { हn }\end{array}$ & $\begin{array}{l}\vec{i} \\
\text { 辛 } \\
\text { fo } \\
\text { fo }\end{array}$ & $\begin{array}{l}= \\
\text { In } \\
\infty \\
m \\
m \\
n\end{array}$ & 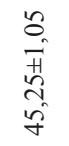 & $\begin{array}{l}2 \\
\infty \\
0 \\
+1 \\
8 \\
f \\
f\end{array}$ & $\begin{array}{l}\text { กี } \\
\text { H } \\
\text { ñ } \\
\text { in }\end{array}$ & 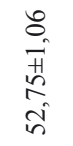 \\
\hline & \multicolumn{3}{|c|}{ 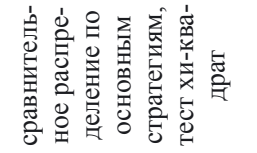 } & $\begin{array}{l}2 \\
0 \\
\hat{n} \\
0\end{array}$ & $\begin{array}{l}0 \\
0 \\
0 \\
\hat{n} \\
0\end{array}$ & $\begin{array}{l}0 \\
0 \\
\hat{0} \\
0\end{array}$ & $\begin{array}{l}2 \\
0 \\
0 \\
\hat{n}\end{array}$ & $\begin{array}{l}0 \\
0 \\
0 \\
\hat{n} \\
0\end{array}$ & $\begin{array}{l}\overline{8} \\
\dot{0} \\
\dot{v} \\
\stackrel{0}{0}\end{array}$ & $\begin{array}{l}2 \\
0 \\
\hat{1} \\
0\end{array}$ & $\begin{array}{l}2 \\
0 \\
0 \\
\hat{n}\end{array}$ \\
\hline & \multirow{4}{*}{ 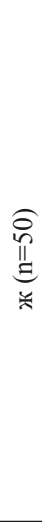 } & \multirow{3}{*}{ 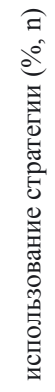 } & 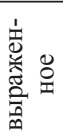 & $\begin{array}{l}\text { क्र } \\
\text { d0 }\end{array}$ & 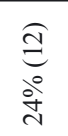 & $\begin{array}{l}\text { శ్ } \\
\stackrel{0}{0} \\
\stackrel{0}{0}\end{array}$ & $\begin{array}{l}\text { E } \\
\text { 움 }\end{array}$ & $\begin{array}{l}\widehat{\sigma} \\
\stackrel{0}{0} \\
\stackrel{0}{\sigma}\end{array}$ & 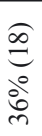 & $\begin{array}{l}\underset{J}{ \pm} \\
\stackrel{0}{\infty}\end{array}$ & $\begin{array}{l}\underset{\Xi}{\Xi} \\
\stackrel{\text { ปे }}{\text { ¿ }}\end{array}$ \\
\hline & & & 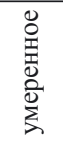 & $\begin{array}{l}\tilde{n} \\
\stackrel{0}{0} \\
\stackrel{0}{0}\end{array}$ & $\begin{array}{c}\overparen{n} \\
\stackrel{0}{2} \\
\stackrel{2}{2}\end{array}$ & $\begin{array}{l}\widetilde{n} \\
\stackrel{0}{0} \\
\stackrel{0}{2}\end{array}$ & 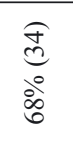 & 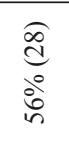 & $\begin{array}{l}\text { ป̀ } \\
\stackrel{\partial}{\dot{y}}\end{array}$ & 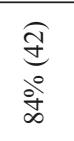 & $\begin{array}{l}\underset{0}{0} \\
\stackrel{0}{+}\end{array}$ \\
\hline & & & 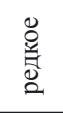 & $\begin{array}{l}\text { E} \\
\stackrel{0}{+} \\
\dot{+}\end{array}$ & ఏீఠ & 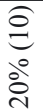 & $\begin{array}{l}\widehat{\varrho} \\
\stackrel{0}{0}\end{array}$ & 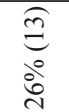 & 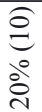 & $\begin{array}{l}\underset{\mathrm{J}}{\stackrel{0}{ }} \\
\stackrel{0}{ }\end{array}$ & $\begin{array}{l}\text { d } \\
\stackrel{0}{+}\end{array}$ \\
\hline & & \multicolumn{2}{|c|}{ 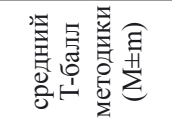 } & $\frac{a}{\pi}$ & $\begin{array}{l}n \\
\infty \\
+1 \\
n \\
n\end{array}$ & 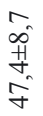 & $\begin{array}{l}n \\
\text { in } \\
0 \\
\therefore\end{array}$ & $\begin{array}{l}0 \\
\infty \\
H \\
1 \\
\infty \\
+\end{array}$ & $\begin{array}{l}\dot{+} \\
\text { +े } \\
\infty \\
\dot{n}\end{array}$ & 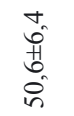 & $\begin{array}{l}\infty \\
0 \\
1 \\
\infty \\
i \\
n\end{array}$ \\
\hline & \multirow{4}{*}{ 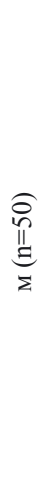 } & \multirow{3}{*}{ 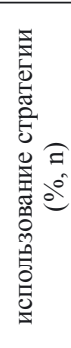 } & 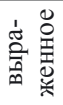 & $\begin{array}{l}\underset{f}{\mathcal{J}} \\
\stackrel{0}{\infty}\end{array}$ & $\stackrel{ }{\mathrm{N}} \Xi$ & $\begin{array}{l}\text { वे} \\
\stackrel{+}{+}\end{array}$ & $\begin{array}{l}\text { क्ठ } \\
b_{0}^{0}\end{array}$ & $\begin{array}{l}\text { क्ठ } \\
\text { di }\end{array}$ & 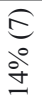 & $\begin{array}{l}\text { (్ర } \\
\text { ठें }\end{array}$ & $\stackrel{\circ}{\stackrel{0}{\circ}} \varrho$ \\
\hline & & & 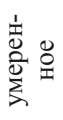 & $\begin{array}{l}\underset{3}{+} \\
\dot{0} \\
\infty\end{array}$ & $\begin{array}{l}0 \\
0 \\
\stackrel{0}{0} \\
\stackrel{0}{N}\end{array}$ & 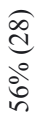 & 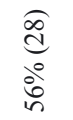 & $\begin{array}{l}\text { dิ } \\
\stackrel{\circ}{\infty} \\
i n\end{array}$ & $\begin{array}{l}\stackrel{\partial}{+} \\
\stackrel{0}{0} \\
\stackrel{\infty}{0}\end{array}$ & 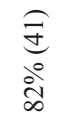 & $\begin{array}{l}\text { م) } \\
\stackrel{0}{0} \\
\stackrel{0}{2}\end{array}$ \\
\hline & & & 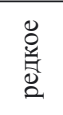 & ถిิ & ఏீఠ & 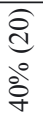 & $\begin{array}{l}\underset{J}{\Xi} \\
\stackrel{0}{0} \\
\text { N }\end{array}$ & 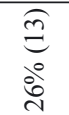 & $\begin{array}{l}\text { (ొ) } \\
\text { d̊ }\end{array}$ & $\begin{array}{l}\text { (e) } \\
\stackrel{\circ}{\text { ป }}\end{array}$ & $\begin{array}{l}\widehat{\sigma} \\
\stackrel{0}{0} \\
0\end{array}$ \\
\hline & & \multicolumn{2}{|c|}{ 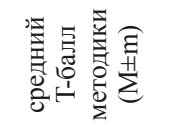 } & $\begin{array}{l}\hat{\sigma} \\
\ddot{n} \\
n\end{array}$ & $\begin{array}{l}\overrightarrow{0} \\
+0 \\
\text { aे } \\
\dot{n}\end{array}$ & \begin{tabular}{l}
$m$ \\
$\infty$ \\
+1 \\
\multirow{y}{y}{}
\end{tabular} & $\begin{array}{l}\overrightarrow{0} \\
\frac{H}{+} \\
\hat{f}\end{array}$ & \begin{tabular}{l}
$n$ \\
\multirow{n}{*}{} \\
$n$ \\
\multirow{y}{*}{}
\end{tabular} & $\begin{array}{l}\text { तू } \\
\text { +1 } \\
\infty \\
\text { n }\end{array}$ & $\begin{array}{l}m \\
\infty \\
+1 \\
\infty \\
\infty\end{array}$ & $\begin{array}{l}2 \\
\text { से } \\
\text { के } \\
\dot{n}\end{array}$ \\
\hline & \multicolumn{3}{|c|}{ 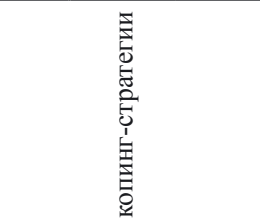 } & 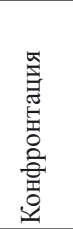 & 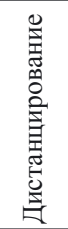 & 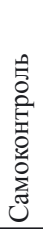 & 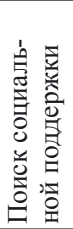 & 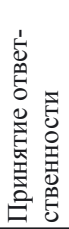 & 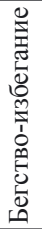 & 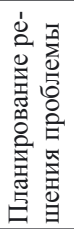 & 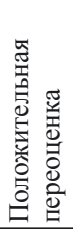 \\
\hline
\end{tabular}


Цифровые показатели выраженности тех или иных копинг-стратегий в группах «М» и «Ж» в основном достоверно не отличались $(\mathrm{p}=0,1-0,7)$, различие выявлено для стратегии «Самоконтроль» $(\mathrm{p}=0,04)$. Это обусловлено более выраженным предпочтением данной стратегии женщинами, в $10 \%$ случаев против 4\% у мужчин (умеренное использование соответствующей стратегии отмечено в 70\% и 56\% случаев, соответственно). Однако методом теста хи-квадрат Пирсона также выявлено достоверное различие по копинг-стратегии «Бегство-избегание» $(\mathrm{p}<0,0001)$. Вероятно, более эмоциональные, по сравнению с мужчинами, женщины в условиях адаптации к конкретной существующей ситуации стремятся как можно избегать эмоциогенных импульсивных поступков, и использовать, по возможности, рациональный подход к проблемным ситуациям

Нами были рассмотрены взаимосвязи копинг-стратерии по шкале 1 «Д-N».

В отсутствие депрессии в группе «М» при достоверности $\mathrm{p}<0,05$ средняя корреляция была выявлена между копинг-стратегиями «Планирование решения проблемы» и «Положительная переоценка» $(\mathrm{r}=0,6)$. «Дистанцирование» и «Бегство-избегание» $(\mathrm{r}=0,6)$, слабая - между стратегиями «Принятие ответственности» и «Положительная переоценка» $(\mathrm{r}=0,5)$, и между «Конфронтация» и «Бегство-избегание» $(\mathrm{r}=0,4)$, «Дистанцирование» и «Самоконтроль» $(\mathrm{r}=0,4)$.

На фоне депрессии в группе «М» при достоверности $\mathrm{p}<0,05$ корреляция средняя корреляция была выявлена между копинг-стратегиями «Самоконтроль» и «Принятие ответственности» $(\mathrm{r}=0,7)$, «Дистанцирование» и «Бегство-избегание» $(\mathrm{r}=0,7)$, «Конфронтация» и «Бегство-избегание» $(\mathrm{r}=0,7)$, «Конфронтация» и «Дистанцирование» $(\mathrm{r}=0,6)$, «Дистанцирование» и «Самоконтроль» $(\mathrm{r}=0,6)$, слабая - между «Конфронтация» и «Положительная переоценка» $(\mathrm{r}=0,5)$, «Дистанцирование» и «Принятие ответственности» $(\mathrm{r}=0,5)$, «Самоконтроль» и «Планирование решения проблемы» $(\mathrm{r}=0,5)$, средняя - между «Планирование решения проблемы» и «Положительная переоценка» $(\mathrm{r}=0,55)$.

В отсутствие депрессии в группе «Ж» при достоверности $\mathrm{p}<0,05$ средняя корреляция была выявлена между копинг-стратегиями «Дистанцирование» и «Бегство-избегание» $(\mathrm{r}=0,6)$, слабая - между «Конфронтация» и «Дистанцирование» $(\mathrm{r}=0,4)$, «Дистанцирование» и «Самоконтроль» $(\mathrm{r}=0,4)$, «Дистанцирование» и «Принятие ответственности» $(\mathrm{r}=0,4)$, «Принятие ответственности» и «Бегство-избегание» $(\mathrm{r}=0,4)$, «Планирование решения проблемы» и «Положительная переоценка» $(\mathrm{r}=0,4)$, «Самоконтроль» и «Бегство-избегание» $(\mathrm{r}=0,35)$. 
На фоне депрессии в группе «Ж» при достоверности $\mathrm{p}>0,05$ средняя корреляция была выявлена между копинг-стратегиями «Конфронтация» и «Поиск социальной поддержки» $(\mathrm{r}=0,7)$, «Дистанцирование» и «Поиск социальной поддержки» $(\mathrm{r}=0,6)$, «Конфронтация» и «Дистанцирование» $(\mathrm{r}=0,6)$, «Принятие ответственности» и «Бегство-избегание» $(\mathrm{r}=$ $0,6)$, «Поиск социальной поддержки» и «Планирование решения проблемы» $(\mathrm{r}=0,5)$.

Показатели маскированных и явных депрессий в группах исследования приведены в Таб. 2.

При оценке показателей депрессии в группах «М» и «Ж» установлено различие таковых по шкалам 1 и 2 (38\% / 26\%, и 4\% /22\%, соответственно).

Считается, что шкала 1 примененной нами методики выявляет два основных фактора - фактор собственно депрессии в узком понимании и фактор тревоги (который включает в себя только «тихие», не связанные с выраженным возбуждением, проявления типа - «я почти всегда о ком-нибудь или о чём-нибудь тревожусь», склонность всё принимать близко к сердцу, испытывать чувство нагромождения трудностей, безнадежности и т.д.). С другой стороны, авторы методики полагают, что нормативная группа здоровых занимает промежуточную зону неопределенного диагноза, то есть область между больными неврозами и МДП; то есть, характерологические признаки шкалы 2 «МДП-Д, неврозы» у здоровых выражены умеренно, тогда как у больных с чётким диагнозом депрессии при неврозах или МДП - в крайней степени) (но, с другой стороны, по их данным. большая доля больных, порядка 40\%, попадает в зону неопределенного диагноза; автор полагает, что это связано как с диагностической недостаточностью шкалы, включающей только утверждения из банка вопросов ММРІ, так и с сутью проблемы, то есть, существованием относительно большой доли больных, которые характерологически сходны со здоровыми, по данным шкалы 2 «МДП-Д, неврозы»).

Взаимосвязь показателей шкал 1 «Д-N» и шкала 2 «МДП-Д, неврозы» определялась как

1. в группе «М» очень слабая отрицательная в отсутствие депрессии $\mathrm{r}=$ $-0,08$ при $\mathrm{p}=0,683$, на фоне депрессии $\mathrm{r}=-0,05$ (статистически незначимая, $\mathrm{p}=0,8)$.

2. в группе «Ж» средняя отрицательная в отсутствие депрессии $\mathrm{r}=$ $-0,5$ при $\mathrm{p}=0,001$, на фоне депрессии очень слабая $\mathrm{r}=0,033$ (статистически незначимая, $\mathrm{p}=0,9)$. 
176 Siberian Journal of Life Sciences and Agriculture, Vol 9, №2, 2017

Таблийа 2.

Показатели маскированных и явных депрессий в группах практически здоровых студентов, находящихся в периоде адаптации к учебному процессу

\begin{tabular}{|c|c|c|c|c|}
\hline \multicolumn{2}{|c|}{ шкала 1 «Д-N» } & \multicolumn{3}{|c|}{ Шкала 2 «МДП - Д, неврозы» } \\
\hline $\begin{array}{l}\text { нет де- } \\
\text { прессии }\end{array}$ & $\begin{array}{l}\text { депрес- } \\
\text { сия }\end{array}$ & $\begin{array}{c}\text { «Т» меньше } 40 \\
\text { баллов - невро- } \\
\text { тический спектр } \\
\text { депрессии }\end{array}$ & $\begin{array}{c}\text { «Т» от } 40 \text { до } 60 \\
\text { баллов - область } \\
\text { диагностической } \\
\text { неопределённости. }\end{array}$ & $\begin{array}{c}\text { «Т» выше } 60 \text { бал- } \\
\text { лов - большая } \\
\text { депрессия. }\end{array}$ \\
\hline \multicolumn{5}{|c|}{ мужчины / женщины (абс., \%) } \\
\hline $\begin{array}{c}\mathrm{n}=31 / \\
37(62 \% / \\
74 \%)\end{array}$ & $\begin{array}{l}\mathrm{n}=19 / \\
13(38 \% \\
/ 26 \%)\end{array}$ & $\begin{array}{c}\mathrm{n}=17 / 10(34 \% \\
/ 20 \%)\end{array}$ & $\begin{array}{c}\mathrm{n}=31 / 29(62 \% / \\
58 \%)\end{array}$ & $\begin{array}{c}\mathrm{n}=2 / 11(4 \% \\
/ 22 \%)\end{array}$ \\
\hline \multicolumn{5}{|c|}{ мужчины / женщины, M \pm m } \\
\hline $\begin{array}{l}56,45 \pm \\
6,31 / 53 \\
65 \pm 7,54\end{array}$ & $\begin{array}{c}93,37 \pm \\
9,37 / \\
79,61 \pm \\
3,37 \\
\end{array}$ & $\begin{array}{c}34,23 \pm 3,37 / \\
33,0 \pm 2,8\end{array}$ & $\begin{aligned} 46,77 & \pm 4,63 / 51,1 \\
& \pm 4,55\end{aligned}$ & $\begin{array}{c}65,5 \pm 2,5 / 66,82 \\
\pm 2,0\end{array}$ \\
\hline \multicolumn{2}{|c|}{$\mathrm{p}<0,001 / \mathrm{p}<0,001$} & \multicolumn{2}{|c|}{$\mathrm{p}<0,001 / \mathrm{p}<0,001$} & \\
\hline & & & \multicolumn{2}{|c|}{$\mathrm{p}<0,001 / \mathrm{p}<0,001$} \\
\hline
\end{tabular}

В отсутствие депрессии в группе «М» по шкале 1 «Д-N» корреляция всех рассмотренных стратегий была в диапазоне от слабой $(\mathrm{r}=0,3)$ до высокой $(\mathrm{r}=-0,8)$. По шкале 2 «МДП-Д, неврозы» определялась статистически значимая $(\mathrm{p}<0,05)$ взаимосвязь только со стратегиями «Конфронтация» $(\mathrm{r}=0,43)$ и слабая с показателем «Дистанцирование» $(\mathrm{r}=0,06)$.

На фоне депрессии в группе «М» по шкалам 1 «Д-N» / 2 «МДП-Д, неврозы» при статистической незначимости $(\mathrm{p}>0,05)$ корреляция всех рассмотренных стратегий была слабой (в диапазоне от $\mathrm{r}=-0,3 /-0,06$ до $\mathrm{r}=$ $0,2 / 0,05)$.

В отсутствие депрессии в группе «Ж» по шкале 1 «Д-N» статистически значимая $(\mathrm{p}<0,05)$ корреляция определялась только по стратегии «Принятие ответственности», и была слабой $(\mathrm{r}=-0,5)$, а по шкале 2 «МДП-Д, неврозы» определялась очень слабая взаимосвязь со всеми копинг-стратегиями ( $\mathrm{r}=$ от $-0,03$ до $\mathrm{r}=0,02)$, статистически незначимая $(\mathrm{p}>0,05)$.

На фоне депрессии в группе «Ж» по шкалам 1 «Д-N» / 2 «МДП-Д, неврозы» корреляция всех рассмотренных стратегий была слабой в диапазоне от $\mathrm{r}=-0,2$ / $-0,01$ до $\mathrm{r}=0,3 / 0,4$, статистически незначимая $(\mathrm{p}>0,05)$.

При решении возникающих в ходе адаптации проблем для этих копинг-стратегий в известном смысле общим является способ их реше- 
ния - в том плане, что отрицание / полное игнорирование проблемы / уклонение от ответственности и действий по разрешению возникших трудностей может принимать форму переключения внимания, отстранения либо обесценивания возникшего вопроса. Это, в свою очередь, позволит снизить / предотвратить эмоциональное напряжение, в том числе посредством уменьшения субъективной значимости возникших затруднений. Но, с другой стороны, при этом вероятно накопление возникших трудностей по причине, в том числе, недооценки значимости и собственных возможностей по преодолению проблемной ситуации.

Вероятно, в данном случае стремление женщин на фоне дистимического состояния скрывать от окружающих свои переживания и побуждения в связи с проблемной ситуацией может базироваться на анализе своего поведение, поиске причин возникших трудностей в каких-то личных недостатках и ошибках действия. Из этого, с одной стороны, может возникнуть понимание личной роли в возникновении создавшихся трудностей и выработка рационального подхода к возникшей ситуации. Но, с другой стороны, возможны трудности выражения переживаний, потребностей и побуждений в связи с проблемной ситуацией (что возможно, обусловлено ситуативной алекситимией), сверхконтроль поведения при необоснованной самокритике и принятия чрезмерной ответственности.

Вместе с тем, известно, что теоретической особенностью шкал, построенных на чисто статистических принципах, является обоснованное выделение статистически значимых для диагностики депрессий утверждений, которые трудно предвидеть клинически, что позволяет впоследствии использовать собственные диагностические подходы, а не повторять в явно ухудшенном виде клиническую беседу.

Так, при анализе вопросов, связанных со здоровьем (соматическим и психическим) установлено, что положительно на вопрос «Состояние моего здоровья примерно такое же, как у большинства моих знакомых» ответило 60\% (30 респондентов) из группы «М» и 70\% (35) из группы «Ж». При этом считают, что «Я вел неправильный образ жизни» $34 \%$ и $20 \%$, соответственно. По совокупности имеющихся проблем «Я часто предаюсь грустным размышлениям» $40 \%$ (20) мужчин и $64 \%$ (32) более эмоциональных женщин $(\mathrm{p}<0,05)$. Они полагают, что «Иногда я чувствую, что близок к нервному срыву» в $30 \%$ (15) и $32 \%$ (16) случаев, соответственно, в том числе и потому, что «Меня очень раздражает, что я забываю, куда кладу вещи» (46\% / 23 и 48\% / 24, соответственно). 
В то же время при анализе работоспособности показано, что «Моя повседневная жизнь заполнена делами, которые мне интересны» у $76 \%$ (38) и $78 \%$ (39) респондентов, соответственно. Они считают «Сейчас я примерно так же работоспособен, как и всегда» в 80\% (40) и 76\% (38) случаев. Это находит свое отражение в утверждении «Принимаясь за какое-нибудь дело, я обычно рассчитываю на успех» в 84\% (42) и 86\% (43) случаев, соответственно, в том числе, потому что «Сейчас я могу судить о вещах лучше, чем когда бы то ни было» в 70\% (35) и 72\% (36), соответственно. С другой стороны, «Бывало, что я целыми днями или даже неделями ничего не мог делать, потому что никак не мог заставить себя взяться за работу» (50\% / 25, и 64\% / 32, соответственно); при этом бывали случаи, что «Мне трудно сосредоточиться на чем-либо одном» $(36 \%$ / 18 , и $38 \% / 19$, соответственно) и «Работа стоит мне большого напряжения» (32\% / 16, и $28 \%$ / 14, соответственно).

На этом фоне имеют место умозаключения, обусловленные в том числе, и имеющимися социально-экономическими тенденциями в обществе. В ряде случаев респонденты считают, что «Временами мне кажется, что я ни на что не годен» (40\% / 20 мужчин, и 36\% / 18 женщин) и «Временами я бываю совершенно уверен в своей никчёмности» $(36 \%$ / 18, и $44 \%$ / 22 , соответственно), потому что «У меня мало уверенности в себе» $(30 \%$ $/ 15$, и $38 \%$ / 19, соответственно). Некоторые утверждают - «Думаю, что я человек обреченный» (по 14\% / 7 в каждой группе), «Определенно, судьба несправедлива ко мне» $(12 \%$ / 6, и $10 \%$ / 5, соответственно), и даже «Будущее кажется мне безнадежным» (16\% / 8, и 6\% / 3, соответственно).

Кроме того, мужчины полагают, что «Если я хочу что-то сделать, но окружающие считают, что этого делать не стоит, я готов отказаться от своих намерений» в 42\% (21 респондент) случаев, а женщины утверждают - «Люди довольно легко могут изменить мое мнение, даже если до этого оно казалось мне окончательным» в 46\% (23) случаев.

\section{Заключение}

Актуальность исследования обусловлена возрастанием нервно-психической нагрузки в начальном периоде адаптации к учебному процессу. Известно, что такие нарушения, как повышенная утомляемость, вялость, головные боли, раздражительность, упадок сил, снижение трудоспособности, ухудшение памяти и внимания, бессонница, головокружение, боли в сердце / в спине / в шее / в суставах, сердцебиение, одышка, врачами общей практики часто расцениваются только как проявление соматиче- 
ского заболевания и не ассоциируются с депрессией; у отдельных пациентов физические симптомы длительное время не находят медицинского объяснения, а психиатры считают подобные симптомы символической интерпретацией психологического конфликта пациентов (соматоформные расстройства) Поэтому сохраняется потребность в прогнозировании и объективизации диагностических критериев раннего выявления нервно-психической дезадаптации - то есть, выявление особенности совладания со стрессовыми и проблемными для личности ситуациями в процессе психосоциальной адаптации

Известно, что в процессе адаптации к учебному процессу студенты испытывают такие основные трудности, как поиск оптимального режима труда и отдыха в новых для них условиях; неумение осуществлять психологическое саморегулирование поведения и деятельности, усугубляемое отсутствием привычки к повседневному контролю педагогов; отсутствие навыков самостоятельной работы, неумение конспектировать, работать с первоисточниками, справочной литературой и т.п.; налаживание быта и самообслуживания, особенно при переходе из домашних условиях в общежитие; отрицательные переживания, связанные с уходом бывших учеников из школьного коллектива с его взаимной помощью и моральной поддержкой; в ряде случаев неопределённость мотивации выбора профессии, и, как следствие, недостаточная психологическая подготовка к ней.

Вместе с тем, в процессе изучения различные виды утомления - физического, умственного, хронического - показано, что студенты 1 курса, находящиеся в процессе адаптации к длительному обучению в ВУЗе, в целом справляются с испытываемыми ими нагрузками, а выявленные у них эмоциональные нарушения имеют субклинический характер [11; 12].

Однако в период сессии нарастающее психоэмоциональное напряжение у студентов может приводить к развитию психологического стресса, который запускается либо реально действующими стрессорами, либо вероятностными событиями (например, ожиданием экзамена) [7]. Считается, что эффективность всех видов копинг-стратегий у больных депрессией зависит от уровня депрессии: чем выше уровень депрессии, тем ниже эффективность используемых ими копинг-механизмов [9].

Поэтому для успешной адаптации студентов к учебному процессу необходимы создание в обучающих группах благоприятного психолого-педагогического микроклимата с целью формирования и индивидуализации умений самоорганизации в соответствии с личностными особенностями студентов; взаимодействие со студентами для преодоления трудностей 
в учебе; раннее выявление студентов группы риска и предупреждение у них возможных нарушений адаптации в период социализации посредством (при необходимости) психодиагностики и консультирования; решения личностных проблем в адаптационный период посредством оказания консультативной или иной другой помощи для предупреждений отклоняющегося поведения

\section{Список литературы}

1. Барденштейн Л.М. Клиника, динамика и терапия дистимий / Александровский Ю.А., Барденштейн Л.М., Аведисова А.С. // Психофамакотерапия пограничных психических расстройств. М.: ГЭОТАР МЕДИЦИНА, 2000. C. $136-162$.

2. Барденштейн Л.М. Клинические критерии, динамика дистимии // Российский медицинский журнал. 2014. № 4. С. 38-40.

3. Березин Ф.Б. Психическая и психофизиологическая адаптация человека. Л.: Наука, 1988. 270 с.

4. Беспалько И.Г. Шкала для экспресс-психологической диагностики слабоструктурированных депрессивных расстройств. СПб: СПб НИПНИ им. В.М. Бехтерева, 2004. 26 с.

5. Вассерман Л.И. [и др.]. Методика для психологической диагностики способов совладания со стрессовыми и проблемными для личности ситуациями. СПб: НИПНИ им. В.М. Бехтерева, 2009. 38 с.

6. Герасимова К.В. Авксентьева М.В., Чикало А.В., Сычев Д.А. Проблема внедрения инновационных технологий персонализированной медицины в клиническую практику в России // Зам. глав. врача. 2012. №3. C. $82-88$.

7. Конарева И.Н. Особенности эмоциональной сферы студентов в период сессии // Психология социализации личности в современных условиях: Сборник статей научно-практ. конф., Симферополь, 10-11.12.2015 г. Симферополь: Изд-во «ДИАЙПИ», 2015. С. 118-123.

8. Лавинский Х.Х., Сычик С.И., Шевчук Л.М., Пронина Т.Н. Персонализированная профилактика // Terra Medica. 2015. №3 (81). С. 9-13.

9. Муравьева О.В., Разуваева Т.Н. Взаимосвязь компонентов структуры личности и копинг-механизмов у больных депрессией // Научные ведомости. Сер. «Гуманитарные науки». 2014. № 6 (177), вып. 21. С. 275-283.

10. Совет Европы: Конвенция о защите личности в связи с автоматической обработкой персональных данных. 2-е изд., доп. СПб: Гражданский контроль, 2002.36 с. 
11. Улюкин И.М., Остроумов И.Н., Болехан В.Н. Смысложизненные установки и самоотношение у студентов первого курса педагогического университета // Вестник психотерапии. 2013. №47 (52). С. 122-133.

12. Улюкин И.М., Остроумов И.Н., Орлова Е.С. Утомление студентов первого курса гуманитарного университета в период адаптации к учебному процессу // Проблемы изучения резистентности организма в действию экстремальных факторов внешней среды: Мат. IX-й научно-практ. конф., Санкт-Петербург, 27.05.2016 г. СПб : ВМедА, 2016. С. 202-207.

13. Флетчер Р., Флетчер С., Вагнер Э.. Клиническая эпидемиология. Основы доказательной медицины, М.: Медиа Сфера, 1998. 352 с.

14. Юнкеров В.И., Григорьев С.Г., Резванцев М.В. Математико-статистическая обработка данных медицинских исследований. СПб.: ВМедА, 2011. $318 \mathrm{c}$.

15. Rochlen A., Whilde M., Hoyer W. The Real Men. Real Depression Campaign: overview, theoretical implications, and research considerations // Psychology of Men and Masculinity. 2005. N 6, pp. 186-194.

\section{References}

1. Aleksandrovskiy Yu.A., Bardenstein L.M., Avedisova A.S. Klinika, dinamika I terepia distimiy [Clinic, dynamics and therapy of dysthymia]. Psikhofarmakoterapia pogranichnykh psikhicheskih rasstroystv [Psychopharmacotherapy of borderline mental disorders]. Moskva, 2000, pp. 136-162 (In Russ.)

2. Bardenstein L.M. Klinicheskie kriterii, dinamika distimii [Clinical criteria, the dynamics of dysthymia]. Rossiyskiy medicinskiy zhurnal [Russian Medical Journal]. 2014. № 4, pp. 38-40.

3. Berezin F.B. Psikhicheskaya I psikhofiziologicheskaya adaptatsia cheloveka [The psychic and psychophysiological human adaptation]. Leningrad, 1988. 270 p. (In Russ.)

4. Bespal'ko I.G. Shkala dlya express-psikhologicheskoy diagnostiki slabostrukturirovannykh depressivnykh rasstroystv [The scale for rapid psychological diagnosis of semistructured depressive disorders]. Sankt-Peterburg, 2004. 26 p. (In Russ.).

5. Vasserman L.I. [et al.]. Metodika dlya psikhologicheskoy diagnostiki sposobov sovladania so stressovymi I problemnymi dkia lichnosti situatsiami [Technique for psychological diagnosis for ways of coping with stressful and problematic situations for the individual]. Sankt-Peterburg, 2009. 38 p. (In Russ.).

6. Gerasimova K.V., Avksentyeva M.V., Chikalo A.V., Sychev D.A. Problema vnedrenia innovatsionnykh tekhnolohiy personalizirovannoy mediciny $\mathrm{v}$ 
klinicheskuyu praktiku v Rossii [The problem of the introduction of innovative technologies of personalized medicine into clinical practice in Russia]. Zamestitil' glavnogo vracha [Deputy Chief Physician]. 2012. №3, pp. 82-88.

7. Konareva I.N. Osobennosti emocional'noy sfery studentov v period sessii [Features of emotional sphere of students during the session]. Psikhologia socializacii lichnosti v sovremennych usloviakh: Sbornik ctatey nauchno-prakt. konf. [Psychology of person socialization in modern conditions: Collected papers of Scient. Conf.]. Simferopol, 10-11.12.2015. Simferopol, 2015. pp. 118-123.

8. Lavinskiy H.H., Sychik S.I., Shevchuk L.M., Pronina T.N. Personalizirovannaya profilaktika [Personalized prevention]. Terra Medica. 2015. №3 (81), pp. 9-13.

9. Murav'iova O.V., Razuvaeva T.N. Vzaimosvyaz' komponentov struktury lichnosti I koping-mekhanizmov u bol'nykh depressiy [The relationship of the individual components of the person structure and coping mechanisms in patients with depression]. Nauchnye vedomosti. Ser. «gumanitarnye nauki» [Scientific sheets. Ser. «Humanitarian sciences»]. 2014. № 6 (177), Iss. 21, pp. 275-283.

10. Sovet Evropy: Konvencia o zashite lychnosti v svyazi s avtomaticheskoy obraborkoy personal'nyh dannyh [The Council of Europe Convention on the Protection of Individuals with regard to Automatic Processing of Personal Data]. Sankt-Peterburg. 2002. 36 p. (In Russ.).

11. Ulyukin I.M., Ostroumov I.N., Bolekhan V.N. Smyslo-zhiznennye ustanovki I samootnoshenie u studentov pervogo kursa pedagogicheskogo universiteta [Meaning-of-life attitudes and self-attidute in the first-year students of pedagogical university]. Vestnik psikhoterapii [The Bulletin of Psychotherapy]. 2013. №47 (52), pp. 122-133.

12. Ulyukin I.M., Ostroumov I.N., Orlova E.S. Utomlenie studentov pervogo kursa gumanitarnogo universiteta $\mathrm{v}$ period adaptacii $\mathrm{k}$ uchebnomu processu [Fatigue of first-year' Humanities University students in the period of adaptation to the educational process]. Problemy izuchenia rezistentnosti organizma $k$ deystviyu extremal'nykh faktorov vneshney spedy: Mat. IX nauchno-prakt. konf. [Problems of studying of the organism resistance to the action of extreme environmental factors: Proc. IX ${ }^{\text {th }}$ scientific-practic. conf.], Sankt-Peterburg, 27.05.2016. Sankt-Peterburg, 2016, pp. 202-207.

13. Fletcher R., Fletcher S., Vagner E. Klinicheskaya epidemiologia. Osnovy dokazatel'noy mediciny [Clinical epidemiology. Basics of Evidence-Based Medicine]. Moskva, 1998. 352 p. (In Russ.).

14. Yunkerov V.I., Grigorjev S.G., Rezvantsev M.B. Matematiko-statisticheskaya obrabotka dannyh medicinskih issledovaniy [Mathematical and statistical processing of medical research data]. Sankt-Peterburg. 2011. 318 p. (In Russ.) 
15. Rochlen A., Whilde M., Hoyer W. The Real Men. Real Depression Campaign: overview, theoretical implications, and research considerations. Psychology of Men and Masculinity. 2005. 6, pp. 186-194.

\section{ДАННЫЕ ОБ АВТОРАХ}

Улюкин Игорь Михайлович, канд. мед. наук, научный сотрудник Федеральное государственное бюджетное военное образовательное учреждение высшего образования «Военно-медицинская академия им. С.М. Кирова»

ул. Академика Лебедева, 6, г. Санкт-Петербург, 194044, Российская Федераиия igor_ulyukin@mail.ru

Григорьев Степан Григорьевич, д-р мед. наук, проф., старший научный сотрудник Федеральное государственное бюджетное военное образовательное учреждение высшего образования «Военно-медииинская академия им. С.М. Кирова»

ул. Академика Лебедева, 6, г. Санкт-Петербург, 194044, Российская Федерация gsg_rj@mail.ru

\section{DATA ABOUT THE AUTHORS}

Uliukin Igor Mikhailovich, PhD Med. Sci., Research Associate

Kirov Military Medical Academy

6, Academic Lebedev Str., St. Petersburg, 194044, Russian Federation igor_ulyukin@mail.ru

SPIN-code: 7606-1700

ResearcherID: L-4093-2016

ORCID: 0000-0001-8911-4458

Grigoriev Stepan Grigorjevich, Dr. Med. Sci., Prof., Senior Research Associate

Kirov Military Medical Academy

6, Academic Lebedev Str., St. Petersburg, 194044, Russian Federation gsg_rj@mail.ru 